\title{
ЯЗЫКОВАЯ ЛИЧНОСТЬ В ХУДОЖЕСТВЕННЫХ ПРОИЗВЕДЕНИЯХ НА АНГЛИЙСКОМ ЯЗЫКЕ НА ПРИМЕРЕ ПОДРОСТКА В ПОВЕСТИ ДЖ. СЭЛИНДЖЕРА «НАД ПРОПАСТЬЮ ВО РЖИ»
}

\section{LINGUISTIC PERSONALITY IN FICTION IN ENGLISH ON THE EXAMPLE OF A TEENAGER IN THE STORY BY J. SALINGER "THE CATCHER IN THE RYE"}

O. Vendina

Yu. Eliseeva

E. Ukhanova

I. Fileshi

Summary: The present stage of development of linguistics is characterized by anthropocentric paradigm of scientific researches which are conducted within psycholinguistics, cognitive linguistics, linguoculturology, etc. Article deals with the one of the basic concepts of the anthropocentric scientific paradigm - linguistic personality. Linguistic personality and its structure is widely discussed in linguistic literature. As many researchers note, the model of a linguistic personality is not a constant, it is open and available for further additions, elaboration and specification. The author of the article highlights the problem of a linguistic personality in the literary discourse. The aim of the research is to study the semantic, stylistic, pragmatic and cognitive speech characteristics of an American teenager based on the story of the American writer J. Salinger "The Catcher in the Rye". The relevance of our research lies not only in the fact that nowadays the linguistic personality of an American teenager is poorly studied and represents a wide field for research. It is important to study the linguistic personality of any literary text because this kind of a linguistic personality is a necessary basis for representing a linguistic personality in a wide context.

Keywords: literary discourse, anthropocentric paradigm, linguistic personality, teenager, "The Catcher in the Rye".

\author{
Вендина Оксана Владимировна \\ к.п.н., доцент, Северо-Кавказский Федеральный \\ университет, г. Ставрополь \\ oksya100@mail.ru
}

Елисеева Юлия Владимировна к.филол.н., дочент, Северо-Кавказский Федеральный университет, г. Ставрополь uliya_uliya@mail.ru

Уханова Екатерина Владимировна к.филол.н., дочент, Северо-Кавказский Федеральный университет, г. Ставрополь Lyubitskaya@mail.ru

Филеши Ирина Владимировна

к.п.н., доцент, Северо-Кавказский Федеральный университет, г. Ставрополь ir.mishencko@mail.ru

Аннотация: Современный этап развития лингвистики характеризуется антропоцентрической парадигмой научных исследований, которые проводятся в рамках психолингвистики, когнитивной лингвистики, лингвокультурологии и других лингвистических направлений. В статье рассматривается одно из базовых понятий антропоцентрической научной парадигмы - понятие языковой личности. Языковая личность и ее структура широко обсуждается в лингвистической литературе. Как отмечают многие исследователи, модель языковой личности не является постоянной, она открыта и доступна для дальнейших дополнений, доработок и уточнений. Автор данной статьи рассматривает вопрос репрезентации языковой личности на материале литературно-художественного дискурса. Целью исследования является изучение лексико-семантических, стилистических, коммуникативно-прагматических и когнитивных характеристик речи американского подростка на материале повести американского писателя Дж. Сэлинджера "The Catcher in the Rye" («Над пропастью во ржи»). Актуальность нашего исследования заключается не только в том, что, с одной стороны, на сегодняшний день языковая личность американского подростка является малоизученной и представляет широкое поле для исследований. Она обусловлена важностью обращения к интерпретации языковой личности литературного героя как необходимой основы репрезентации языковой личности в широком контексте.

Ключевые слова: литературно-художественный дискурс, антропоцентрическая парадигма, языковая личность, подросток, «Над пропастью во ржи»
B последние годы существенно повысился интерес к изучению языка как феномена, имеющего личностное начало. Внедрение антропоцентрической парадигмы в лингвистические исследования привело к рассмотрению и описанию языковых явлений в контексте их тесной взаимосвязи с человеком, его сознанием, миропониманием, менталитетом и национально-культурными особенностями. В связи с этим на арену лингвистических исследований выходит понятие языковой личности.

«Языковая личность» как термин, укрепившийся в 
лингвистике, тесным образом связан с понятием личности, которое функционирует во многих гуманитарных науках - философии, социологии, психологии и других. С точки зрения философии под личностью понимается «всякое существо, способное создавать абсолютные ценности и руководиться ими в своем поведении» [6, с. 14]. Социология рассматривает личность как «продукт общественного развития», как индивида, который включается «в систему социальных отношений посредством активной предметной деятельности и общения» [8, с. 222]. В психологии, первой обратившейся к исследованию личности, данное понятие рассматривают как совокупность эмоций, мотиваций, мыслей, переживаний и восприятий человека, которые обеспечивают формы его поведения, относительно устойчивые во времени и меняющихся ситуациях действительности. Личность, как считают зарубежные психологи, проявляется в поведении индивида и обусловливает его специфические качества и их комбинации, которые отличают данную личность от другой и образуют ее индивидуальные различия [11, с. 22]. Но ведь личность - это не только человек с определенным набором внешних и внутренних характеристик. Всякая личность проявляется через язык, носителем которого она является. На основе текстов, созданных личностью, можно судить о ее отношении к миру и достижении определенных целей в жизни, о ее психологических качествах и уровне социализации в обществе, о ее взаимосвязи со своим этносом и национальных проявлениях этнокультурного поведения. Так было введено понятие языковой личности, которое впервые появилось в труде Лео Вайсгербера под названием «Родной язык и формирование духа» (1927), в котором немецкий лингвист развил идеи своего предшественника, В. фон Гумбольдта, высказавшего идею о связи человека с его родным языком. Употребляя термин «языковая личность» (sprachliche Persönlichkeit), ученый связывает понятие личности с основными характеристиками языка как

1) силы «народного духа»;

2) носителя культуры;

3) носителя истории.

Все эти особенности отражены в языковой картине мира носителей языка, который, используя язык, проявляет себя как личность, вобравшая общенациональные черты и общечеловеческие качества. Ученый доказывает, что действенность родного языка прослеживается на протяжении всего развития языковой личности [2].

В отечественных исследованиях понятие «языковая личность» было впервые зафиксировано в первой половине XX века в размышлениях В.В. Виноградова о Бодуэне де Куртенэ, которого «интересовала языковая личность как вместилище социально-языковых форм и норм коллектива, как фокус скрещения и смешения разных социально-языковых категорий» [3, с. 61]. Но в своих исследованиях языковой личности Виноградов делает упор на художественную литературу, считая, что литературные произведения помогают раскрыть индивидуально-речевую структуру личности. По Виноградову, те виды словесности, которыми оперирует персонаж художественного произведения (прецедентные феномены, рассказы, анекдоты, каламбуры и др.) персонифицируют личность, являются показательными для ее внешней и внутренней характеристики.

Дальнейшая разработка понятия языковой личности в отечественных исследованиях принадлежит Ю.Н. Караулову, который в своей классической работе «Русский язык и языковая личности» (1987) дает каноническое определение языковой личности как «совокупности способностей и характеристик человека, обусловливающих создание им речевых произведений (текстов)» $[5$, с. 3]. Российский ученый разработал уровневую модель языковой личности с опорой на художественный текст. Согласно его теории, языковая личность имеет три структурных уровня. Нулевой уровень - вербально-семантический - отражает степень владения бытовым языком. На этом уровне исследуется лексикон языковой личности (лексические единицы и выражения, посредством которых индивид общается с членами языкового коллектива). Первый уровень - лингвокогнитивный (тезаурусный) актуализирует и идентифицирует релевантные знания и представления, которые свойственны члену социума как языковой личности. Базовыми единицами этого уровня являются концепты, идеи. В процессе анализа языковой личности этот уровень является особенно интересным, т.к. предполагает изучение языковой модели отдельно взятого индивида в контексте взаимосвязи с национально-языковой моделью мира. Поэтому в процесс анализа включаются пословицы, поговорки, крылатые выражения, фразеологические единицы. Третий уровень (самый высокий) - это мотивационно-прагматический уровень. Он охватывает характеристику мотивов и целей, управляющих развитием языковой личности, обусловливающих ее поведение и участвующих в сознании текстов, которые определяют иерархию смыслов и ценностей в ее языковой модели.

В структуру понятия «языковая личность» В.А. Маслова включает следующие компоненты:

1) ценностный, мировоззренческий компонент, то есть систему ценностей;

2) культурологический компонент, то есть уровень овладения культурой, которая является эффективным средством повышения интереса к языку;

3) личностный компонент, предполагающий то индивидуальное, что существует в каждом человеке и формируется через внутреннее отношение языку $[7$, c. 81].

Зарубежные исследователи также активно обращаются к изучению языковой личности, языковые особен- 
ности которой они связывают с функциональным анализом текстов (прежде всего, художественных) [14, с. 56]. С точки зрения зарубежных лингвистов, художественный текст представляет собой сложное коммуникативное явление, состоящее не только из авторской речи, но и из речи персонажей-коммуникантов, которой свойственна и стилистическая маркированность, и определенные грамматические модели, и своеобразный лексикон, который имеет внешнюю (диалоговую) и внутреннюю (несобственно-прямая речь) форму. Конечно, языковая личность персонажа художественном текста есть плод воображения писателя, но, с другой стороны, представленная в различных ситуациях общения, она несет в себе как индивидуальные черты, так и ментальную культуру нации в целом.

В контексте репрезентации понятия «личность» С позиций психологической науки исследователей чаще всего интересует юношеский период. Однако ученые-лингвисты очень неохотно обращаются к изучению языковой личности литературного героя подросткового возраста. А ведь еще в 20-х гг. минувшего столетия В.В. Малаховский подчеркивал: «Юность не безразлично относится к слову. Наоборот, вкус к слову, к его выразительности чрезвычайно повышается в период юности. Особенное внимание юношество отдает качественной стороне речи: ее яркости, эмоциональности, изобретательности. Стиль юности необуздан и романтичен. Юность любит выражаться своеобразно, сильно. Отсюда стремление юности отойти от речевого шаблона, найти свои слова и выражения, отсюда любовь юности к экзотическим словам...» [цит. по: 1, с. 58]. На наш взгляд, в данном ключе интерес для исследователей представляет языковая личность главного героя повести Дж. Сэлинджера "The Catcher in the Rye" («Над пропастью во ржи»), особенности которой раскрываются, в первую очередь, через индивидуальный лексикон, являющийся «средством экспликации индивидуального образа мира» [12, с. 21]. По мнению Л.Н. Чурилиной, «специфика слова как единицы индивидуального словаря, "живого слова индивида", проявляется в том, что оно перестает быть только конвенциональной единицей, то есть единицей, имеющей системное значение, в силу неизбежной осложненности индивидуальными смыслами. Как и любое слово в тексте, слово персонажа обретает свою собственную значимость, нередко выходящую за пределы семантических дефиниций словаря, а иногда имеющую с ними мало общего» [12, с. 22]. Именно в данном ключе следует рассматривать языковую личность Холдена Колфилда, героя повести "The Catcher in the Rye". Шестнадцатилетний подросток, который уже не ребенок, но еще и не взрослый, ведет жизнь вполне обычную, благополучную, но внутренне он словно обитает «в другом измерении» [9, c. 479]. На протяжении всей повести Холден вечно дурачится, паясничает и разыгрывает потешные клоунады, пародирует голливудские фильмы. У героя неопреде- ленное будущее, он испытывает отвращение ко всем профессиям, уважаемым в обществе. Сэлинджер выбирает самую экспрессивную из возможных жанровых форм - форму исповеди, в связи с чем доминирующей формой презентации речи персонажа в произведении является монолог. Именно эта форма репрезентации речи, как считает О.А. Филимонова, «позволяет автору наиболее полно и открыто выразить точку зрения героя на конкретное событие, раскрыть его взгляды и убеждения» $[10$, с. 10].

Главный герой повести Дж. Сэлинджера "The Catcher in the Rye" использует различные регистры речи: от высоко пафосного до низкого грубого. Причем языковые единицы различных стилей речи можно обнаружить в пределах одного текстового отрезка, например, в самом начале повествования:

"If you really want to hear about it, the first thing you'll probably want to know is where I was born, and what my lousy childhood was like, and how my parents were occupied and all before they had me, and all that David Copperfield kind of crap, but I don't feel like going into it, if you want to know the truth. In the first place, that stuff bores me, and in the second place, my parents would have about two hemorrhages apiece if I told anything pretty personal about them" [13, p. 21].

Как мы видим, в речи героя перемежаются грубопросторечная лексика (crap, stuff), книжно-литературные лексические единицы (truth, childhood, personal, occupу и др.) и даже научные термины (hemorrhage)

Вульгарной лексики в речи Холдена немного, но сленг с различными неодобрительными значениями употребляется часто. Сниженная разговорная лексика и сленг используются для выражения особенностей обычной речи американского школьника; в ситуациях, связанных с выражением эмоционального, экспрессивного состояния, настроения героя; в ситуациях оценки рассказчиком предметов и явлений действительности. Существующая реальность осмысляется героем, в основном, негативно, состояние можно определить как состояние на краю «пропасти». Поэтому оценочная лексика имеет сниженный характер. При этом речь Холдена эмоциональна, экспрессивна, чему как раз и способствует использование разговорной лексики и сленга.

Итак, выделим основные группы языковых единиц, встречающихся в речи героя произведения.

1. Разговорная лексика и фразеологические выражения:

1. Собственно разговорная лексика и фразеологические выражения: kind of, regular, terrific, guy, stupid, or anything, and all, dorm, terrifically, boy, puke, drive crazy, mad about, up alley, corny, okay, terrific, stuff, pot of, pile of, buddy, phony, crazy, kill, terrible, goner, kid, moron, sore at, all right, fix up, crazy about, sort of, cut 
out, screw up, booze, sexy, gorgeous, old, nosy, no kidding, horse manure и т.д.

2. Неодобрительная лексика и фразеологические выражения: goddam, damn, the hell, like hell, the hell out (of), as hell, helluva (hell of a), just for the hell of it, not give a damn, for Chrissake, Jesus, shut up.

\section{II. Сленг.}

1. Собственно сленг: dough, hotshot, for the birds, hit the ceiling, lousy, stink, knock out, horse around, buck, up the creek, babe, yap, have all marbles, snotty, hot one, shack up, screwball, gal, putrid, beat it и т.д.

2. Сленг с пометами «вульгарный», «грубый»: crap, ass, half-assed, fat-assed, my ass, bastard, fart, fuck и т.д.

Наиболее частотными в монологе героя являются лексемы hell и ass.

Так, автор повести во всевозможных синтаксических конструкциях, характеризующие внутреннюю речь героя, использует эмфатический усилитель hell (или, изредка, его эвфемистический эквивалент heck). Эти конструкции употребляются:

- в сравнениях: touchy as hell, old as hell, charming as hell, sad as hell, cold as hell, dirty as hell, mad as hell, rusty as hell, playful as hell, bourgeois as hell, descriptive as hell, beautiful as hell, bale like hell, shiver like hell, chatter like hell, etc.;

- в слитных глагольных словосочетаниях (collocations) для усиления предлогообразного наречия; get the bell out, clear the hell out, bang the hell out, slide way the hell down, way the bell off, stand way the hell up, etc.;

- в сочетании с глаголом для придания выражению обратного значения: the hell he did - «черта с два он это сделал»: like hell it is - «ну да», «еще чего», «черта с два», еtс.;

- в сочетании с вопросительными местоимениями: where the hell, when the hell, what the heck, what the bell, how the bell, etc.;

- в отрицательных конструкциях: hope to hell not, etc.;

- вместо усилительных оборотов адвербиального характера при глаголе: it annoyed hell out of old Ackley; that annoyed bell out of me; my Gladstones kept banging hell out of my legs; it fascinated hell out of her; it scared boll out of old Phoebe; that, depressed the hell out of me, etc.;

- во фразеологических сочетаниях: beat hell out of somebody - «разбить кого-либо в пух и прах, одержать полную победу»; just for the hell of it - «просто так», еtc.;

- в качестве восклицания: hell, if I ...; hell, no! etc.

В свое речи герой часто использует грубо-просто- речное слово ass, которое употребляется:

— в прямом значении: freezing my ass off; neither of us felt like sitting around on our ass all night; snapping his soggy old, wet towel at people's asses, etc.;

- в переносном значении: a nice old guy that didn't know his ass from his elbow; something that gives me a royal pain in the ass, etc.;

- в качестве восклицания: lovely my ass: strange my ass, etc.;

- в качестве словообразовательных элементов: in a half-assed way; back-asswards, etc.

Еще одной частотной лексемой в монологе Холдена является определение goddam. В большинстве случаев данная лексема употребляется рассказчиком для негативной оценки неприятных ему предметов, явлений американской действительности. Анализ употребления данного прилагательного позволяет перечислить те реалии американской жизни, которые вызывают возмущение героя. Это элитные школы Элктон-Хилс (Elkton Hills), военные школы (military school), школьные секретные общества (secret fraternity), школьные классы (class), традиционные футбольные матчи в школах (game), учителя (schoolteacher), клетчатые куртки, указывающие на принадлежность к элитным школам (checkered vests), члены школьного общества интеллектуалов (intellectuals), книжного клуба (Book-of-the-Month Club), молодежные вечеринки (party), радиопостановки (mystery program), кинофильмы (movies), концерты в развлекательном центре Радио-Сити (first show at Radio City Music Hall), спектакли в театрах (play), каток в Радио-Сити (rink), деньги (money), дорогие машины Кадиллак (Cadillac), улица Бродвей (Broadway), гостиницы (hotel), лифты (elevator), залы ресторанов (room), бары (bar), официанты (waiter), полицейские (сор), высшие офицеры (general), суды (trial), такси (cab), автобусы (bus), велосипеды (bicycle), обочины тротуаров (curb), тротуары (side of the street), Голливуд (Hollywood), кладбища (cemetery).

Как видим, почти все, что окружает Холдена, может определяться им как «проклятое» ("goddam”). Р.Д. Орлова так объясняет высокую частотность употребления стилистически сниженной лексики по отношению к обычным предметам: «Все, о чем он говорит, - а он говорит почти обо всем, - «отвра-тительное», «чертово», «проклятое». Все вместе, без разбору, в одной куче: Бродвей, кино, парк, театральные билеты. Даже ни в чем не повинные коньки - и те «подлые». На вещи он переносит то, что ему отвратительно в людях, человеческих отношениях» [цит. по: 4, с. 294]. Реалии американской жизни, окружающие героя, вызывают в нем потребность выражать свои мысли именно таким образом. В сознании Холдена, по-видимому, существует ассоциативная связь «других» людей, «другого» мира с бранными выражениями.

Итак, разговорная лексика, фразеологизмы и сленг в 
речи подростка используются

1) для выражения особенностей обычной речи американского школьника,

2) в ситуациях, связанных с выражением эмоционального, экспрессивного состояния, настроения героя,

3) в ситуациях оценки рассказчиком предметов и явлений действительности.

Однако в финальной части романа герой пытается стереть со стены школы вульгарную надпись "Fuck уои". Это важный эпизод для понимания процесса примирения героя с миром, который вызывает в нем тошноту и боль. "Somebody'd written 'Fuck you' on the wall. It drove me damn near crazy. <...> I hardly even had the guts to rub it off the wall with my hand, if you want to know the truth. <...> But I rubbed it out anyway, finally" [13, c. 279].

Эта надпись для героя символизирует пошлость действительности. Холден воображает, как она становится поводом для гнусного рассказа подростка, появляется во всех местах, где он пытается скрыться, даже на могильной плите. В конце концов герой приходит к выводу: "If you had a million years to do it in, you couldn't rub out even half the "Fuck you» signs in the world. It's impossible" [13, c. 280].
Приведенное высказывание героя - одно из ключевых в романе. Хол- ден осознает бессмысленность борьбы с прописными истинами «на заборах», идет по пути искренности в отношениях с людьми, преодолевая коммуникативные неудачи.

Итак, в процессе исследования мы выявили, что языковая личность представляет собой сложное явление с многоуровневой организацией. Она обладает своим неповторимым набором личностных качеств и языковым сознанием. Языковая личность есть личность, выражающая совокупность социальных, физических, психологических, эмоциональных, прагматических и других характеристик в языке.

На наш взгляд, структура языковой личности подростка, представленной в художественном произведении, представляет собой интерес для лингвистического исследования. Мы исследовали этот тип языковой личности на примере главного персонажа повести Дж. Сэлинджера "The Catcher in the Rye" и пришли к выводу, что речь тесным образом связана Холдена Колфилда связана не только с особенностями его подростковой психологии, согласно которой все видится в «черном цвете», поэтому является отражением негативных эмоций, по и коррелирует с его внутренним миром, символом которого является одиночество.

\section{ЛИТЕРАТУРА}

1. Анищенко 0.А. Генезис и функционирование молодежного социолекта в русском языке национального периода. - М.: Флинта, $2010 .-340$ c.

2. Вайсгербер Й.Л. Родной язык и формирование духа. - М.: Едиториал УРСС, 2004. - 232 с.

3. Виноградов В.В. 0 языке художественной прозы. - М.: Наука, 1980. - 360 с.

4. История американской литературы: В 2 ч. / Под ред. Н.И. Самохвалова. - М.: Просвещение, 1971. - Ч. 2. - 544 с.

5. Караулов Ю.Н. Русский язык и языковая личность. - М: КомКнига, 2006. - 264 С.

6. Лосский Н.О. Учение о перевоплощении. Интуитивизм. - М.: Прогресс, 1992. - 207 с.

7. Маслова В.А. Лингвокультурология. - М.: Академия, 2001. - 208 с.

8. Социологический словарь / отв. ред. Г.В. Осипов, Л.Н. Москвичев;. - М.: Норма, 2008. - 608 с.

9. Толмачев В.М., Седельник В.Д., Иванов Д.А. и др. Зарубежная литература XX века. - М.: Академия 2003. - 640 с.

10. Филимонова 0.А. Бытийная и характеризующая пропозиции в смысловой организации художественного текста (на материала перевода и оригинала романа Дж.Д. Сэлинджера «Над пропастью во ржи»): Автореф. дисс. ... канд. филол. наук. - Томск, 2007. - 19 с.

11. Хьелл Л., Зиглер Д. Теории личности. - СПб.: Питер, 2007. - 607 с.

12. Чурилина Л.Н. «Языковая личность» в художественном тексте : монография. - М.: Флинта : Наука, 2011. - 240 с.

13. Salinger J.D. The Catcher in the Rye. - M. Kapo, 2009. - 288 c.

14. Salkie R. Text and discourse analysis. - London, NY: Routledge, 1995. -115 p.

( Вендина Оксана Владимировна (oksya100@mail.ru), Елисеева Юлия Владимировна (uliya_uliya@mail.ru), Уханова Екатерина Владимировна (Lyubitskaya@mail.ru), Филеши Ирина Владимировна (ir.mishencko@mail.ru). 